\title{
One big bowl of dust
}

Nat. Commun. 9, 2867 (2018)

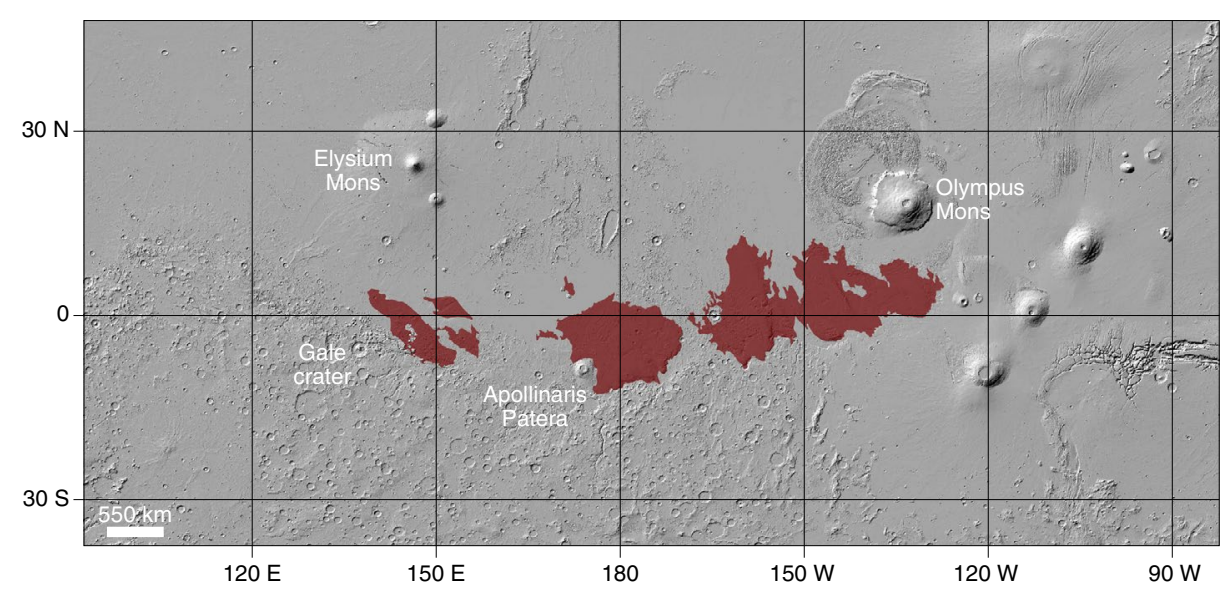

Credit: Springer Nature Ltd

Dust plays a key role in the Martian system and climate, of which the monthslong global dust storms are just the most dramatic representation, and is present almost ubiquitously on the surface of Mars. Now, Lujendra Ojha and collaborators propose that Martian dust comes primarily from a single reservoir.

Martian dust is enriched in sulfur (S) and chlorine $(\mathrm{Cl})$ and has a specific $\mathrm{S}: \mathrm{Cl}$ ratio of $3.7 \pm 0.7$. Ojha et al. analysed global elemental maps from the Gamma Ray Spectrometer onboard the Mars Odyssey spacecraft and found that only one region satisfied every observational constraint: the Medusae Fossae Formation (MFF), a large $\left(\sim 2 \times 10^{6} \mathrm{~km}^{2}\right)$ sedimentary unit (shown in red in the image) located close to the big Tharsis volcanoes. Intriguingly, it has been suggested (L. Kerber et al. Icarus 216, 212-220; 2011) that the MFF was formed by ash produced by nearby volcanism. This origin fits the observed high values of $\mathrm{S}$ and $\mathrm{Cl}$.

The scenario suggested by Ojha et al. implies that the MFF was significantly larger in the past, in agreement with previous studies (B. A. Bradley et al. J. Geophys. Res. $107,5058 ; 2002)$, and is progressively being emptied as the dusty ash is redistributed by atmospheric circulation. Quantitative estimates indicate that the MFF has contributed to Martian dust as much as all of the other known reservoirs put together.

\section{Luca Maltagliati}

Published online: 22 August 2018 https://doi.org/10.1038/s41550-018-0575-0 